\title{
SEO for Your Optometry Practice: The Secret Sauce That Still Tastes Great in 2020
}

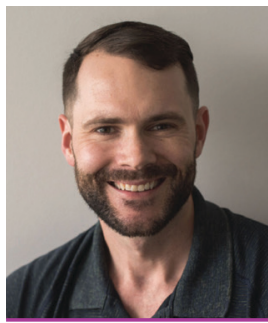

Cameron Martel, Manager - SEO \& Content Solutions @ 4ECPs

Cameron Martel is an experienced digital marketer, managing SEO and content campaigns since 2005. He currently works with dozens of eye care practices through his work with Marketing4ECPs. He's colorblind, but don't remind him or he'll be seeing red (or so he thinks).Cam can be reached at www.marketing4ecps.com or cameron@4ecps.com.

I

'm going to let you in on a little SEO (search engine optimization) secret that most SEO professionals don't want you to know: for most optometrists, SEO isn't hard... and it doesn't have to be complicated, either. But, thanks to years of tomfoolery by nefarious "SEO professionals," business owners feel that SEO is the opposite of simple.

Do you feel that way as well? If so, we want to change that today.

\section{WHAT SEO ISN'T}

Shady SEO professionals have existed since search engines became a thing, and they're notorious for promising results and making guarantees that they never seem to deliver on. It's not surprising that many optometrists equate SEO to a black box of bamboozling and mystery.

In light of that, before we get into what SEO is, let's talk about what it isn't:

- A mystery - SEO should be a transparent process, with clear workflow items and timelines.

- Expensive - An investment in SEO is generally in line with other types of performance marketing. If you're being quoted high, ask for a breakdown of where that budget is going.

- Siloed - SEO should never exist on its own as your sole marketing method. Always supplement it with traditional media and performance marketing tactics.

- Fast - It can take a few weeks before SEO efforts show results (Google can be slow in determining where a website consistently sits in its index).

\section{WHAT SEO IS}

Now that you know what SEO isn't, let's outline what it is:

- Transparent - SEO work isn't intangible; it's a mix of blog strategy, content creation, reputation management, and website technical oversight.

- Affordable - SEO doesn't have to be expensive unless you plan on ranking on a national or international scale.

- About the Searcher - The more value you add to the equation (from the user's perspective), the stronger your SEO will be. 
- Measurable - You can measure things, such as organic traffic (in Google Analytics), to see the impact of your SEO efforts over time. Think in quarters versus days or weeks.

\section{THE SECRET SAUCE THAT OPTOMETRISTS PAY TOO MUCH MONEY TO LEARN}

Whether you are managing your SEO yourself, or if you want to be able to better understand and measure your SEO team, you'll want to build a strategy that is some variation of the components below. I've listed these items in my preferred order of importance:

1. Make sure you have your Google My Business profile claimed and optimized - It's not enough to just claim it. Optimize it by:

a. Adding photos of your practice interior/exterior, team members, logo, etc.

b. Ensuring the name/address/phone number is consistent with what is listed on your website, as well as major directory/profile sites (such as YellowPages.ca, Yelp!, LinkedIn, etc.).

c. Responding to reviews, good or bad.

2. Nail your website fundamentals - Make sure your website follows the technical best-practices that are widely published throughout the web (Moz has a good guide on this one). A few specifics that really matter in SEO today:

a. Have a dedicated page on your website for each medical service like Dry Eye.

b. Make sure your website loads fast (under three seconds on desktop, two and a half seconds on mobile).

c. Make it easy to get to any page/post on your site in three clicks or less.

3. Build your "About Us" page into an awesome experience - This matters, and not just because your "About Us" page is likely in the top-10 most viewed pages on your website. This is where you demonstrate your expertise, which Google is increasingly prioritizing.

4. Own your social media profiles and use them - I recommend focusing on Facebook and YouTube, as they are the easiest platforms for your audience to engage you on. Be effective and create content that generates engagement (and discussion).

5. Create a blog experience worth reading (and then fill it full of great content) - The more awesome content you have, the better Google will view you and the more traffic it will send your way.

6. Share your content with industry peers, relevant websites, and local social media channels - Get your content in front of your audience, and even better- get them talking about it.

THAT'S IT: NOW YOU'VE GOT THE SECRET SAUCE

If the above sounds simple, that's because it is. Once your website is in a good spot, your SEO strategy shifts to focus on creating great content and getting your community talking about you.

That's SEO in 2020, and likely for 2021, too. • 